\title{
Assessment of Pregnant Women Knowledge and Practices Concerning Iron Deficiency Anemia at Al-Amara City/Iraq
}

\author{
Ghazwan Abdulhussein AlAbedi ${ }^{1}$, Aqeel Aziz Arar ${ }^{2}$, Mustafa Salim Abdul Alridh ${ }^{3}$ \\ ${ }^{1}$ MSc. Academic Lecturer. Department of Community Health Nursing, College of Nursing/University of Misan, \\ Misan, Iraq, ${ }^{2}$ MSc. Academic Lecturer, Department of Adult Nursing. College of Nursing/ University of Misan, \\ Misan, lraq, ${ }^{3}$ MSc. Academic Lecturer, Department of Pediatric Nursing, College of Nursing/ University of Misan, \\ Misan, lraq
}

\begin{abstract}
Objectives: To assess knowledge and practices related to the prevention of iron deficiency anemia among pregnant women and to find an association between their knowledge; practices and socio-demographic variables. Methodology: This is an institutional descriptive study conducted on the random selection of six primary healthcare centers in Al-Amara city. A purposive sampling technique was used to select (280) pregnant mothers attending antenatal care service.

Results: Almost half of the sample belongs to the primary education level $(50.3 \%)$ and most of them housewife $(56.8 \%)$, with low monthly income $(71.8 \%)$. Over three quarters of the sample had moderate knowledge $(76.1 \%)$ and their unfavorable practices $(75.5 \%)$ with regard to iron anemia. The results indicated a high relationship between the knowledge and practice of women with the variables under study $(p=0.000)$.

Conclusion: The study concluded that the majority of participants have insufficient knowledge with moderate practices towards preventing this type of anemia. Health education about foods with a high concentration of iron is an essential step towards reducing iron deficiency anemia in pregnant women.
\end{abstract}

Key words: Knowledge, Practice, Iron Deficiency Anemia, Pregnant Women.

\section{Introduction}

Iron deficiency anemia (IDA) is one of the most common problems between under-nutrition and public health problems worldwide with the highest prevalence in developing countries ${ }^{(1)}$. Anemia of iron means that without a sufficient amount in the blood, the body cannot produce enough red blood cell material to enable it to transport oxygen (Hemoglobin); as a result, the IDA may make women feel tired and restless ${ }^{(2)}$. Pregnant women are at increased risk for IDA due to increased blood volume during pregnancy resulting from increased support to the fetus and placenta. In general, women in childbearing stage suffer from the loss of large amounts

\section{Corresponding author:}

Ghazwan Abdulhussein AlAbedi

ghazwanabdulhussein@uomisan.edu.iq of blood due to childbirth or menstruation, which are factors contributing to the development of iron anemia (3)

The World Health Organization (WHO) estimates showed in 2011, 32.4 million (38\%) of pregnant women, while 496 million (29\%) of those who are not pregnant between the ages of 15-49 years suffer from anemia. Moreover, previous studies on IDA have revealed a prevalence of $73.9 \%$ in Guyana, 22.1\% in Egypt, 39.7\% in Kuwait, $78.0 \%$ in Liberia, and $50.0 \%$ in Bahrain ${ }^{(4)}$. In Iraq, the Nutrition Research Institute showed, through a section of research and studies, the prevalence of iron deficiency among pregnant women $38 \%$ and nonpregnant $25 \%$, respectively ${ }^{(5)}$. Iron deficiency in body leads to disorder in metabolism and reduced immunity in the pregnant women and become vulnerable to attack of infectious agents. Anemia is a major health problem but can be addressed through increased awareness and 
adherence to healthy eating practices ${ }^{(6)}$. The increased risk of developing IDA during pregnancy and lactation has prompted most ministries and governmental and nongovernmental bodies in many countries to implement policies to provide iron supplementation for pregnant and lactating women ${ }^{(3)}$.

Good knowledge and eating iron-rich foods when preparing food at home by women to prevent iron deficiency varies depending on the culture and awareness of women. While lower maternal education is associated with a higher incidence of low-birth weight, neonatal death in infants, and prematurity of women with severe iron deficiency ${ }^{(7)}$.

Maintaining a woman's health through healthy behavior represented by eating healthy foods is among the most important protective factors in achieving optimal health ${ }^{(3)}$.

\section{Objective}

1. To assess the pregnant woman's knowledge towards Iron deficiency anemia.

2. To assess the woman's practices concerning Iron pregnancy anemia.

3. To found out relationship between the participants knowledge and practices with their sociodemographic data.

\section{Methodology}

Quantitative design (A descriptive study) was applied in the study during the period $3^{\text {rd }}$ November 2019 at $30^{\text {th }}$ January 2020 . A simple random sample is used to select (6) out of 16 primary health care centers PHCs at Al-Amara city. Convenient purposive sampling technique was adopted for (380) pregnant women visiting antenatal care units for preventive or therapeutic reasons, these women were collected from the six centers which include (63) women from Shaheed Al-Watan, (64) from AL-Askan, (63) pregnant women from Al-Quds, (62) Nahawnd center, (64) and (64) from Al-Aruba and AL-Ermuk PHCs respectively. The participants were selected according to predetermined criteria including which include pregnant women and more than one gravida. While the excluded criteria which include female non pregnant and non married. The interview technique was used to collect sample data through the use of constructive questionnaires by researchers to achieve the goals of this study through the use of the Arabic version, which contains three parts: The first part related to socio-demographic information which comprised of (6) items, and the second part to assess of knowledge for pregnant women toward Iron anemia it consists of (34) items. It comprises of (6) section which including (General information about IDA, the causes, symptoms of this type of anemia, the negative effects, the benefit of intake iron pills during pregnancy, and knowledge of pregnant women about food that contains a high concentration for iron. Finally, the section three it concerned with women's behaviors (practices) during the current pregnancy which contains (15) items related to IDA. The content validity of the tool was established by (8) experts. These items were rated according to the three likert scale: (Knowledge and practices) I know / or Always (3); Uncertain / or Sometime (2), and I do not known / or Never scored as (1). The measurement was scored by using cut-of-point intervals $(1.00-1.66)$ low; moderate (1.67-2.33), and (2.34-3.00) high, as well as $(\mathrm{L}),(\mathrm{M})$, and $(\mathrm{H})$ respectively.

Data were analyzed using Statistical Package of social sciences (SPSS) version 20. Then the results were calculated using descriptive statistics such as percentage, frequency, and Mean of Score, standard deviation, and inferential statistics through ANOVA test to find out correlation between knowledge of the pregnant women and practices regarding IDA. The results were affirmed as significant at $\mathrm{P} \leq 0.05$ and not significant at $\mathrm{P}>0.05$.

\section{Results}

There is a quarter of the participants $97(25.5 \%)$ of study sample within the age group ( $20-24$ years), while 119(31.3\%) of pregnant women had their first pregnancy. Concerning to the level of educational is showed half of pregnant women 191(50.3\%) in the study sample were primary school graduate. Regarding the subject of occupational status represented the majority of pregnant were $216(56.8 \%)$ housewives. In relation to the monthly income the majority were $273(71.8 \%)$ have less than $(<700000$ Iraqi Dinar). However sources of information concerning iron deficiency anemia the majority of pregnant women were $215(56.6 \%)$, they receive their information from health center / mother \& child care. 
Table (1): Assessment of Participant Level toward the Knowledge and Practices Concerning IDA

\begin{tabular}{|c|c|c|c|c|}
\hline \multirow{2}{*}{ Participants' Level } & \multicolumn{2}{|c|}{ Knowledge. } & \multicolumn{2}{|l|}{ Practices } \\
\hline & Frequency & Percent & Frequency & Percent \\
\hline Low & 73 & 19.2 & 54 & 14.2 \\
\hline Moderate & 289 & 76.1 & 287 & 75.5 \\
\hline High & 18 & 4.7 & 39 & 10.3 \\
\hline Total & 380 & 100.0 & 380 & 100.0 \\
\hline$\overline{\mathrm{x}} \mp \mathrm{S} . \mathrm{D}$ & \multicolumn{2}{|c|}{${ }_{1.77} \mp 0.276 \mp 0.276$} & \multicolumn{2}{|c|}{${ }_{1.95} \mp \mathbf{0 . 2 7 8} \mp \mathbf{0 . 2 7 8}$} \\
\hline
\end{tabular}

$\overline{\mathrm{x}} \mp$ S. D. $\overline{\mathrm{x}} \mp$ S. D.=Arithmetic Mean $(\overline{\mathrm{x}}) \overline{\mathrm{x}})$ and Std. Dev. (S.D.), Participant Levels: (1.00 - 1.66) = Low ;( 1.67 $-2.33)=$ Moderate; $(2.34-3.00)=$ High.

This table reveals that the majority of women have a moderate level of knowledge and practices related to iron anemia ( $\mathrm{n}=380 ; 289(76.1 \%), 287(75.5 \%))$ respectively.

Table (2): Assessment of Main Domains Related to Pregnant Women's Knowledge

\begin{tabular}{|l|l|l|l|l|l|}
\hline No. & Overall Main Domains & N & M. S. & S. D. & Ass. \\
\hline 1 & What do you know about iron deficiency anemia? & 380 & 1.58 & 0.413 & L \\
\hline 2 & The causes of IDA. & 380 & 1.61 & 0.367 & L \\
\hline 3 & The symptoms of anemia for Iron. & 380 & 1.69 & 0.322 & M \\
\hline 4 & The negative effects of IDA. & 380 & 1.73 & 0.438 & $\mathbf{M}$ \\
\hline 5 & The benefit of intake iron pills during pregnancy & 380 & 1.69 & 0.322 & $\mathbf{M}$ \\
\hline 6 & Food that contains a high concentration of iron. & 380 & 1.91 & 0.339 & $\mathbf{M}$ \\
\hline
\end{tabular}

n= sample size, S.D= Standard Deviation, M.S= Mean of Score, Ass. = Assessment, Assessment Levels: (1.00 1.66) Low; Moderate $=(1.67-2.33)$, and $(2.34-3.00)=$ High.

The results of the above table show the major domains related to pregnant knowledge regarding iron deficiency anemia have mean of score were moderate level, based on the answers of pregnant women, except domains (1\&2) demonstrated mean of score were low level.

Table (3): Assessment of Women's Practices Concerning IDA

\begin{tabular}{|c|c|c|c|c|c|c|c|c|c|c|}
\hline \multirow{2}{*}{ No. } & \multirow{2}{*}{$\begin{array}{l}\text { Items of Women's behaviors } \\
\text { during the current pregnancy }\end{array}$} & \multicolumn{2}{|c|}{ Always } & \multicolumn{2}{|c|}{ Sometime } & \multicolumn{2}{|c|}{ Never } & \multirow{2}{*}{ M. S. } & \multirow{2}{*}{ S. D. } & \multirow{2}{*}{ Ass. } \\
\hline & & $\mathbf{F}$ & $\%$ & $\mathbf{F}$ & $\%$ & $\mathbf{F}$ & $\%$ & & & \\
\hline 1 & You drink tea with meals & 55 & 14.5 & 289 & 76.0 & 36 & 9.5 & 2.05 & 0.487 & M \\
\hline 2 & You take iron pills daily & 115 & 30.3 & 265 & 69.7 & - & - & 2.30 & 0.460 & M \\
\hline 3 & $\begin{array}{l}\text { You take iron pills with orange } \\
\text { juice }\end{array}$ & 52 & 13.7 & 212 & 55.8 & 116 & 30.5 & 1.83 & 0.644 & M \\
\hline
\end{tabular}


Cont... Table (3): Assessment of Women's Practices Concerning IDA

\begin{tabular}{|c|c|c|c|c|c|c|c|c|c|c|}
\hline 4 & $\begin{array}{l}\text { You take iron pills with milk or } \\
\text { with its derivatives }\end{array}$ & 65 & 17.1 & 168 & 44.2 & 147 & 38.7 & 1.78 & 0.716 & M \\
\hline 5 & You eat breakfast daily & 16 & 4.2 & 289 & 76.1 & 75 & 19.7 & 1.84 & 0.465 & M \\
\hline 6 & You eat lunch daily & 113 & 29.7 & 243 & 63.9 & 24 & 6.3 & 2.23 & 0.554 & M \\
\hline 7 & You eat dinner every day & 108 & 28.4 & 169 & 44.5 & 103 & 27.1 & 2.01 & 0.746 & M \\
\hline 8 & You take iron pills before eating & 27 & 7.1 & 167 & 43.9 & 186 & 48.9 & 1.58 & 0.622 & $\mathrm{~L}$ \\
\hline 9 & You take iron pills after eating & 18 & 4.7 & 160 & 42.1 & 202 & 53.2 & 1.52 & 0.588 & $\mathrm{~L}$ \\
\hline 10 & $\begin{array}{l}\text { You eat fruits about half an hour } \\
\text { before meals }\end{array}$ & 34 & 8.9 & 214 & 56.3 & 132 & 34.7 & 1.74 & 0.609 & M \\
\hline 11 & You eat fish & 24 & 6.3 & 215 & 56.6 & 141 & 37.1 & 1.69 & 0.583 & M \\
\hline 12 & You eat eggs daily & 152 & 40.0 & 217 & 57.1 & 11 & 2.9 & 2.37 & 0.540 & $\mathrm{H}$ \\
\hline 13 & You eat red meat & 70 & 18.4 & 159 & 41.8 & 151 & 39.7 & 1.79 & 0.733 & M \\
\hline 14 & You eat chicken & 156 & 41.1 & 167 & 43.9 & 57 & 15.0 & 2.26 & 0.703 & M \\
\hline 15 & $\begin{array}{l}\text { You eat legumes (chickpeas, } \\
\text { lentils, and beans) }\end{array}$ & 103 & 27.1 & 268 & 70.5 & 9 & 2.4 & 2.25 & 0.484 & M \\
\hline
\end{tabular}

Table (3) shows that all items related to practices of iron deficiency anemia have mean of score were moderate level, depending on the responses of pregnant women, except items (8\&9) presented low level.

Table (4): Association between Knowledge of the pregnant women with Their Demographic Characteristics

\begin{tabular}{|c|c|c|c|c|c|c|}
\hline $\begin{array}{l}\text { Knowledge } \\
\text { Variables }\end{array}$ & $\begin{array}{l}\text { Sources of } \\
\text { Variance. }\end{array}$ & $\begin{array}{l}\text { Sum of } \\
\text { Squares }\end{array}$ & df. & $\begin{array}{l}\text { Mean } \\
\text { Square }\end{array}$ & F. & Sig. \\
\hline \multirow{2}{*}{ Age (years) } & Between Groups & 26.395 & 4 & 6.599 & \multirow{2}{*}{43.684} & \multirow{2}{*}{0.000} \\
\hline & Within Groups & 56.645 & 375 & 0.151 & & \\
\hline \multirow{2}{*}{$\begin{array}{l}\text { Number of Pregnancies } \\
\text { (multipara) }\end{array}$} & Between Groups & 48.537 & 7 & 6.934 & \multirow{2}{*}{74.758} & \multirow{2}{*}{0.000} \\
\hline & Within Groups & 34.503 & 372 & 0.093 & & \\
\hline \multirow{2}{*}{ Level of Education } & Between Groups & 32.512 & 4 & 8.128 & \multirow{2}{*}{60.323} & \multirow{2}{*}{0.000} \\
\hline & Within Groups & 50.528 & 375 & 0.135 & & \\
\hline \multirow{2}{*}{ Occupational Status } & Between Groups & 19.796 & 2 & 9.898 & \multirow{2}{*}{59.005} & \multirow{2}{*}{0.000} \\
\hline & Within Groups & 63.243 & 377 & 0.168 & & \\
\hline \multirow{2}{*}{ Monthly Income } & Between Groups & 2.036 & 2 & 1.018 & \multirow{2}{*}{4.738} & \multirow{2}{*}{0.009} \\
\hline & Within Groups & 81.003 & 377 & 0.215 & & \\
\hline \multirow{3}{*}{$\begin{array}{l}\text { Sources of Information } \\
\text { Concerning IDA }\end{array}$} & Between Groups & 36.006 & 3 & 12.002 & \multirow{3}{*}{95.946} & \multirow{3}{*}{0.000} \\
\hline & Within Groups & 47.034 & 376 & 0.125 & & \\
\hline & Total & 83.039 & 379 & & & \\
\hline
\end{tabular}

Findings of the table -4- show that there is a very significant relationship between the knowledge of a pregnant woman about IDA with their demographic characteristics at ( $p$ value $<0.05$ ). 
Table (5): Association Between the pregnancy Practices with Their Demographic Characteristics

\begin{tabular}{|c|c|c|c|c|c|c|}
\hline $\begin{array}{l}\text { Practice } \\
\text { Variables }\end{array}$ & $\begin{array}{l}\text { Sources of } \\
\text { Variance }\end{array}$ & $\begin{array}{l}\text { Sum of } \\
\text { Squares }\end{array}$ & df & $\begin{array}{l}\text { Mean } \\
\text { Square }\end{array}$ & $\mathbf{F}$ & Sig. \\
\hline \multirow{2}{*}{ Age (years) } & Between Groups & 18.962 & 4 & 4.741 & \multirow{2}{*}{24.204} & \multirow{2}{*}{0.000} \\
\hline & Within Groups & 73.446 & 375 & 0.196 & & \\
\hline \multirow{2}{*}{$\begin{array}{l}\text { Number of Pregnancies } \\
\text { (multipara) }\end{array}$} & Between Groups & 28.376 & 7 & 4.054 & \multirow{2}{*}{23.551} & \multirow{2}{*}{0.000} \\
\hline & Within Groups & 64.032 & 372 & 0.172 & & \\
\hline \multirow{2}{*}{ Level of Education } & Between Groups & 36.869 & 4 & 9.217 & \multirow{2}{*}{62.234} & \multirow{2}{*}{0.000} \\
\hline & Within Groups & 55.539 & 375 & 0.148 & & \\
\hline \multirow{2}{*}{ Occupational Status } & Between Groups & 20.446 & 2 & 10.223 & \multirow{2}{*}{53.557} & \multirow{2}{*}{0.000} \\
\hline & Within Groups & 71.962 & 377 & 0.191 & & \\
\hline \multirow{2}{*}{ Monthly Income } & Between Groups & 15.983 & 2 & 7.991 & \multirow{2}{*}{39.421} & \multirow{2}{*}{0.000} \\
\hline & Within Groups & 76.425 & 377 & 0.203 & & \\
\hline \multirow{3}{*}{ Sources of Information } & Between Groups & 32.598 & 3 & 10.866 & \multirow{3}{*}{68.312} & \multirow{3}{*}{0.000} \\
\hline & Within Groups & 59.809 & 376 & 0.159 & & \\
\hline & Total & 92.408 & 379 & & & \\
\hline
\end{tabular}

Data analysis in this table indicates a high correlation between the practices of women towards iron anemia and its demographic data at ( $\mathrm{p}$ value $=0.00$ ).

\section{Discussion}

Our study is one of the few investigations that aim to collect special data related to the knowledge, and practices of pregnancy towards IDA in the city of AlAmara / in southern of Iraq. Based on the results, the researchers concluded that the majority of pregnant mothers who visit pregnant care units have moderate or weak knowledge and behaviors in preventing iron deficiency anemia. Reports indicate that iron deficiency is the main cause of anemia that some pregnant women still suffer, and it is the most common nutritional disorder in many countries ${ }^{(8)}$. This reason may be the result of a high prevalence of anemia in developing countries, including the low socioeconomic situation that causes a lack of awareness of a diet containing high amounts of iron. AlAbedi et., al ${ }^{(9)}$, who mentioned in their study that aimed To assess women's knowledge about pregnancy risks, the majority of participants does not have enough monthly income which is due to the poor financial situation in the country or most of the women are housewives with a low educational level.

As for women's knowledge and practices about causes and symptoms, negative effects of anemia and methods of prevention by taking iron pills or iron food supplement during pregnancy, it appears at a low to moderate level in our study. This result may be due to a low level of education because the majority have primary schools or because of a lack of experience resulting from the fact that most of them are in the first or second pregnancy. This result was supported by Ghimire and Pandey ${ }^{(1)}$, who showed that more than half of the sample (51.3\%) and (66.0\%) had inadequate knowledge and poor practice in prevention of IDA. Also, AlAbedi et., al (2019) ${ }^{9}$ who found in study which conducted in Iraq the majority of participants (35.3\%) and (42.0\%) have low and moderate knowledge respectively on risk factors during pregnancy, including iron-containing nutrients. 
Practices and knowledge of the women for IDA has high significant relationship with increase of age, educational qualification, No. of pregnancies, employment, income status and sources of information at ( $\mathrm{p}$ value $>0.01)$. This result was agree with a study conducted in India/Pune by Sivapriya and Parida (2015)

${ }^{10}$ Who found that there is a great relationship between information and practices of participants about IDA with socio-demographic data for study participants.

\section{Conclusion}

The results of our study concluded that pregnant women need to improve their knowledge, which in turn enhances their practices. Therefore, the bad and moderate practice towards the prevention of iron anemia is one of the main factors that contribute to an increased incidence of iron deficiency anemia in Al-Amara City.

\section{Recommendation}

Based on the results of the study, primary health care nurses play a vital role by providing health education to women in pregnant care units that focuses on increasing their knowledge of the causes and symptoms of anemia and preventing it by taking iron supplements and eating iron-rich foods during pregnancy. Hence, the researcher emphasizes the need for more research to improve the knowledge and practices of mothers on anemia during pregnancy.

Financial Disclosure: There is no financial disclosure.

Conflict of Interest: None to declare.

Ethical Clearance: All experimental protocols were approved under the Department of Community Health Nursing and all experiments were carried out in accordance with approved guidelines.

\section{References}

1. Ghimire N, Pandey N. Knowledge and Practice of Mothers Regarding the Prevention of Anemia During Pregnancy, in Teaching Hospital, Kathmandu, Journal of Chitwan Medical College. 2013; 3: 14-17.
2. Raut B K. Jha M K. Shrestha A. Sah A. Sapkota A. Byanju S. Malla S S. Prevalence of iron deficiency anemia among pregnant women before iron Supplementation in Kathmandu university Hospital/ Dhulikhel Hospital, Journal of Gynecology and Obstetrics.2014; 2: 54-58.

3. Souganidis E S, Sun K, Pee S, Kraemer K, Rah J, Pfanner R M. Sari M. Bloem M W. Semba R D. Relationship of maternal knowledge of anemia with maternal and child anemia and health-related behaviors targeted at anemia among families in Indonesia, Matern Child Health J. 2012; 16: 19131925.

4. World Health Organization (WHO): Global Nutrition Targets 2025 Anaemia Policy Brief, Geneva. 2014; 1-8.

5. Nutrition research institute Iraq, Wheat flour fortification, Iraq. 2014; 1-24.

6. Singh I. Singh H. and Kaur D. Evaluation and comparison of knowledge, attitude and practice about iron deficiency anemia amongst medical students of rural and urban background, International Journal of Research in Medical Sciences. 2015; 3: 1342-1344.

7. Tashara I F. Achen R K. Quadras R. D'Souza $\mathrm{M}$ V. Jyothi P J. Knowledge and self-reported practices on prevention of iron deficiency anemia among women of reproductive age in rural area, International Journal of Advances in Scientific Research. 2015; 1: 289-292.

8. Ali F, Al-Ani AS. Prevalence of iron deficiency anemia among adolescents intermediate school pupils in Ramadi District. Iraqi journal of community medicine 2000; 22: 158-162.

9. AlAbedi GA, Arar A, Radhi TA. Assessment of Knowledge for Pregnant Women toward Risk of Pregnancy in Al-Amara Primary Health Care Centers at Southern of Iraq. Indian Journal of Public Health. 2019; 10: 57 .

10. Sivapriya S M. \& Parida L A. study to assess the knowledge and practices regarding prevention of anemia among antenatal women attending a tertiary level hospital in Pune. Int J Sci Res NET. 2015; 4:1210-14. 